\title{
Diabetes: mellitus or lipidus?
}

\author{
E. Shafrir, I. Raz \\ Department of Medicine, Diabetes Research Centre, Hadassah University Hospital, Jerusalem, Israel
}

\section{Introduction}

Since ancient times the search for causes of diabetes was related to the sweetness of urine and other body fluids. In England, Thomas Willis (1621-1675) was among the first to taste the urine of diabetic patients and declare that "its sweet taste was imbued with honey sugar" with the supposition that it was derived from blood. This finding led to the addition of "mellitus" to the word diabetes.

We should reconsider whether the definition of diabetes as mellitus is justified. The traditional emphasis on the insulin-glucose axis with respect to examining glucose tolerance, although diagnostically useful does not explain the basic pathophysiological mechanisms operating in diabetes. The glucose-insulin axis has been overemphasised, while alterations in the insulin to non-esterified fatty acid (NEFA) ratio and metabolism received much less attention both as diabetes derangement and as diagnostic potential. Perhaps this is partly due to the fact that the techniques for glucose measurements have been considerably simplified for home use, whereas the measurement of NEFA and triglycerides is still encumbered with relative difficulties, being more expensive and time consuming.

Received: 10 September 2002 / Revised: 5 November 2002 Published online: 14 March 2003

C) Springer-Verlag 2003

Corresponding author: Dr. E. Shafrir, Department of Medicine, Diabetes Research Centre, Hadassah University Hospital, Ein Kerem, Jerusalem, 91120 Israel

E-mail: shafrir@md.huji.ac.il

Abbreviations: DAG, diacylglycerol; LCFA CoA, long chain fatty acid coenzyme $\mathrm{A}$; $\mathrm{PKB}$, protein kinase $\mathrm{B}$; $\mathrm{PKC}$, protein kinase $\mathrm{C}$; TZD, thiazolidinediones.

\section{NEFA as the main fat energy supplier, affected by diabetes and obesity}

The major change in the appreciation of the nature of molecules supplying body energy came with the discoveries by Dole [1] and Gordon and Cherkes [2] that plasma NEFA are the major lipid transporters in the mammalian organism. Furthermore, NEFA are the only form of fat release from adipose tissue, subject to hormonal regulation [3]. The very rapid turnover of plasma NEFA indicates that they are an important fuel, which even in non-fasting conditions are the energy source to body tissues equivalent to or greater than glucose. Early data on the role of NEFA in glucose homeostasis were reviewed in 1969 by Ruderman et al. [4]. The importance of FFA in the regulation of gluconeogenesis was extensively dealt with, but no clear pathogenic conclusion with relation to major diabetes perturbations emerged at that time.

The effect of hyperinsulinaemia after a glucose load on patterns of NEFA response in normal and diabetic subjects is shown (Fig. 1). The gradual decrease of plasma NEFA concentrations reached a nadir of about $200 \mu \mathrm{mol} / \mathrm{l}$ at $1 \mathrm{~h}$. Non-obese patients with mild Type 2 diabetes showed a decrease in NEFA to a similar and even more protracted nadir than normal subjects most probably because of facilitated uptake of NEFA by tissues in the presence of compensatory hyperinsulinaemia. Patients of two additional groups with high resistance to insulin responded with a more limited NEFA decline pattern and with a higher and shorter NEFA nadir indicating a sustained presence of high NEFA in the circulation and insulin resistance in adipose tissue. The NEFA response is highly sensitive and provides information supplementary to the glucose curve on the patient's response in this situation [5].

Obesity or diabesity as such is another example of fat metabolism abnormality in Type 2 diabetes, whether 


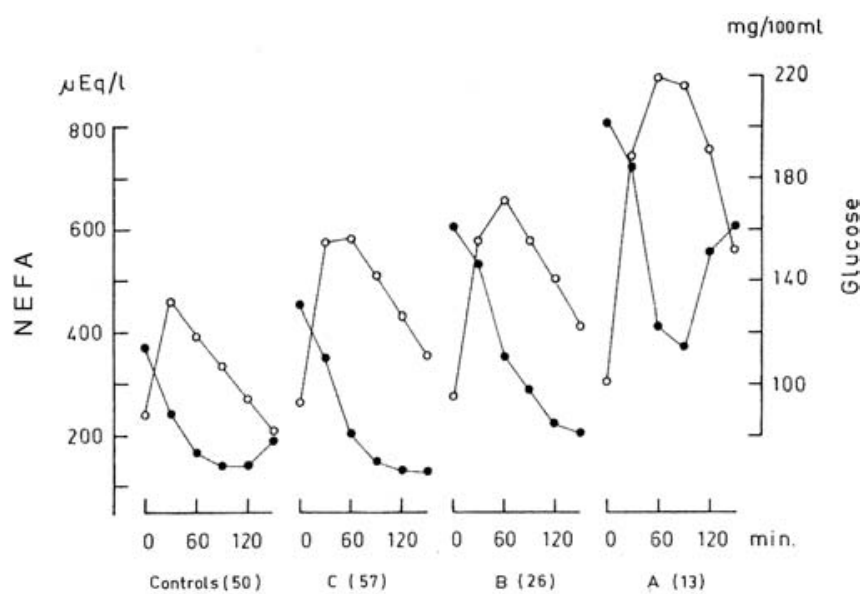

Fig. 1. NEFA - and glucose $\bigcirc-\bigcirc$ curves during glucose load of $1 \mathrm{~g} / \mathrm{kg}$ in 50 control and 96 patients with IGT or Type 2 diabetes, all non-obese (BMI 24 to $28 \mathrm{~kg} / \mathrm{m}^{2}$ ). The patterns of NEFA decline where divided as "Group C" $(n=57)$ - nadir similar to controls but occurring later than in control patients, at 60 min and lasting up to 150 min. "Group B" $(n=26)$ NEFA decrease not reaching the nadir of the control groups even at 150 min. "Group A" $(n=13)$ nadir of NEFA much higher than normal, lasting only $30 \mathrm{~min}$ between 60 and $90 \mathrm{~min}$, most probably related to the high preload NEFA value. The higher initial concentrations of NEFA and the high nadirs in groups A and $\mathrm{B}$ indicate lower lipolysis restraint in adipose tissue in addition to the impaired glucose tolerance (unpublished investigations of E. Shafrir and A. Gutman based on [5])

due to deficiency of lipostatic hormone or to insulin + glucose promotion of fat deposition. The mechanism of adipose tissue weight gain will not be elaborated here, although diabesity should definitely be looked upon as an aspect of fat metabolism aberration.

It is important to mention at this point that Zierler and Rabinowitz [6] showed in 1964, that infusion of a very small amount of insulin $\left(10 \mu\right.$ units $\left.\cdot \mathrm{min}^{-1} \cdot \mathrm{kg}^{-1}\right)$ through the brachial artery in human forearm leads to a significant decrease in plasma NEFA concentrations and an increase in tissue potassium uptake without any concomitant effect on glucose uptake. This finding leads to the conclusion that the restraint of NEFA release (from adipose tissue) is the most sensitive action of insulin on the lipolysis regulation in comparison with other insulin effects and does not involve the translocation of glucose to promote NEFA retention by esterification.

The lack of restraint of NEFA mobilisation in hypoinsulinaemia leads to a marked plasma NEFA increase, ectopic deposition of triglycerides, insulin resistance and defect in glucose uptake by muscles. The latter fact stresses the effect of excessive availability of NEFA on the reduction of the insulin-mediated muscle glucose utilisation as shown in the classic experiments of Randle et al. [7, 8]. It involves a reduction of muscle glycolysis by inhibiting phosphofructokinase by rising cytosolic concentrations of citrate and consequent accumulation of glucose 6-phosphate. Pyruvate dehydrogenase is also inhibited by rising mitochondrial concentrations of acetylCoA and the NADH:NAD ratio. In the liver, the same changes in redox ratio and activation of pyruvate carboxylase by acetylCoA result in stimulation of gluconeogenesis. This is a further instance of the effect of NEFA oversupply as a contribution to hyperglycaemia in diabetes.

Life-threatening events can occur when the heart NEFA inflow becomes excessive. In acute myocardial ischaemia, it is often associated with fatal ventricular arrhythmia and fibrillation. NEFA have been implicated as a risk factor for sudden cardiac death in diabetes $[9,10]$. The arrythmogenic effect of NEFA, related to acute coronary syndrome, is elicited by rapid catecholamine release and massive NEFA mobilisation from adipose tissue. The regional switch in myocardial substrate metabolism to increased fat use elicits reduction in glucose uptake, resistance to insulin action and increase in mitochondrial NEFA oxidation, leading to oxygen crisis.

In pronounced hypoinsulinaemia, when the NEFA supply from adipose tissue escapes control, not only total body glucose homeostasis is disrupted, but the resultant ketosis and acidosis become life-threatening. It is of interest to recall here McGarry's thoughts of Minkowski's failure to identify ketonuria [11] during his seminal experiments with dogs after pancreatectomy [12]. McGarry hypothesised that if Minkowski had been aware of the ketone odour of urine rather than of its sweetness, the importance of the deranged fat metabolism in diabetes would have been recognised sooner.

The eminent Randle glucose-NEFA cycle concept appears, however, to hold only in severe NEFA oversupply in conditions similar to Type 1 diabetes. The effect of lipid infusion in healthy volunteers and the results of a glucose load in obese and insulin-resistant diabetic patients in a euglycaemic clamp system have been investigated [13]. The increased NEFA concentrations in the circulation in these groups, in the presence of insulin, resulted only in relatively moderate decreases in glucose uptake, non-oxidative metabolism and glucose storage with greater utilisation of the fat substrate. The hepatic glucose production was not abolished, which in the presence of increased NEFA availability became non-suppressible by insulin.

The causes for the diminished muscle glucose uptake before the onset of overt diabetes have been extensively reviewed $[14,15,16]$. Convincing evidence that an increase in NEFA concentration, whether due to increased endogenous mobilisation or to postabsorptive lipolysis on a fat-rich diet, is associated with triglyceride deposition in muscle, liver and other tissues, eliciting insulin resistance. Other studies have also indicated that the early perturbations in glucose metabolism as a result of augmented fatty acid utilisation during lipid infusion are gradual [17]. Whole body glucose uptake decreased to about one half of 
the control after $6 \mathrm{~h}$, augmented lipid oxidation was associated with a fourfold reduction in oxidative glucose metabolism, including glycogen synthesis by $3 \mathrm{~h}$ and the decrease in muscle glucose-6-phosphate concentration already by $1.5 \mathrm{~h}$ of infusion. Further evidence has shown that NEFA reduce the insulin-stimulated glucose transport and phosphorylation and whole body glucose clearance in human volunteers [18]. Thus, preceding the changes described by Randle et al. [7], the first effect of FFA-induced insulin resistance is the restriction of glucose cell entry, followed by reduction in its metabolism, including the incorporation into glycogen.

The intracellular muscle triglyceride deposition in subjects susceptible to diabetes was documented by numerous investigators $[19,20,21,22,23]$ and shown to attenuate glucose metabolism. The earliest observed perturbations are retardation in GLUT4 trafficking reducing the glucose entry into muscle cells [24]. These early changes indicate that phosphatidylinositol-3-kinase (PI3K), regulating GLUT4 translocation to the cell membrane, is affected by reduced IRS tyrosine phosphorylation. Reduction in muscle fat by diet restriction in experimental models of diabesity, the OLETF rats [25] caused an impressive improvement in IGT and in muscle glucose uptake. Similar results were reported in patients with morbid obesity, in which dietary fat deprivation lowered muscle triglycerides, as assessed by histochemistry, ameliorated insulin resistance and increased GLUT4 expression [26]. Also, weight loss after gastric bypass surgery in morbid obese patients resulted in increased insulin sensitivity and reduction in muscle long chain fatty acid CoA (LCFACoA) esters [27].

As discussed in depth by McGarry [28], accumulation of muscle triglycerides results in an increased intracellular LCFACoA concentration, due to lipolysis of the enlarged cell pool of triglycerides. LCFACoA lead to impairment of glucose uptake and insulin resistance through the inhibition of mitochondrial palmitoyl carnitine transferase (CPT) responsible for their transport into the mitochondria and oxidation. The delay in LCFACoA transport causes an increase in the cellular intermediates of triglyceride synthesis and breakdown, with accumulation of intermediates, particularly diacylglycerol (DAG) [29, 30] (Fig. 2). A similar increase in LCFACoA occurs by inhibiting CPT with etomoxir [31]. DAG is not only an outcome of increased triglyceride turnover, but could also be produced by phospholipase $\mathrm{C}$ cleavage of diacylinositol phosphates.

\section{Causative alterations in tissue fat metabolism leading to Type 2 diabetes: DAG and PKC}

The outcome of LCFCoA and DAG accumulation is the attenuation of the insulin signalling pathway at
Muscle fat turnover

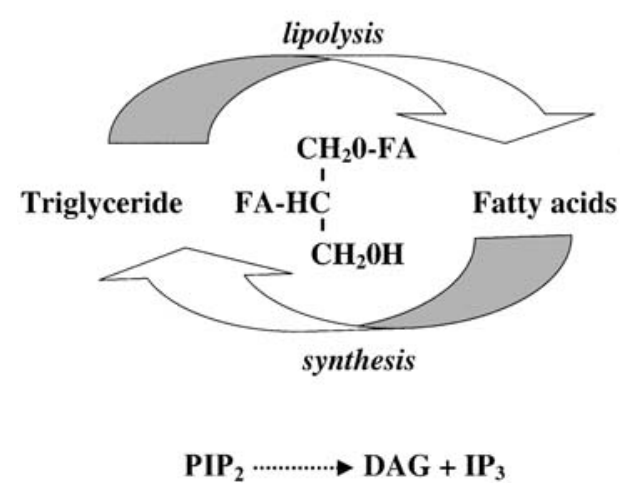

Fig. 2. Source of tissue diacylglycerol (DAG). Synthesis of triglycerides from glucose or intracellular lipolysis of preformed triglycerides involves diacylglycerol as an intermediate. This could also include long-chain fatty acyl CoA (LCFACoA) which accumulate within the cells when their entry into the mitochondria is retarded. Action of phospholipase $\mathrm{C}$ on phosphatidylinositol-diphosphate $\left(\mathrm{PIP}_{2}\right)$

several points. DAG induces an overexpression of isoenzymes of the PKC group, e.g. PKC $\theta$ [32] and PKCE $[33,34,35]$. Referring to the conjunction of muscle triglycerides, DAG and PKC, in vitro uptake of NEFA by smooth muscle cells increases DAG concentrations with time of incubation and with NEFA concentration [36]. An extensive review of the effects of DAG-sensitive and DAG-independent members of the PKC family is available [37].

The DAG-sensitive PKC isoenzymes are known to phosphorylate serine and threonine on several protein components of the insulin signalling pathway causing a negative feedback in signal transduction $[38,39,40$, $41,42]$. Inhibition of PKC activity was shown to relieve the insulin signalling attenuation [43]. One of the results of PKC-DAG interaction is the reduction of glucose uptake in insulin-sensitive tissues as manifested by inhibition of P13K detachment from the IRS and failure to activate and/or translocate GLUT4 vesicles. A strongly reduced concentration of GLUT4 protein and mRNA was seen in the insulin-resistant PKCE overexpressing Psammomys obesus [33, 34], a desert gerbil, prone to nutritionally-induced insulin resistance. The increase in muscle DAG was associated with deficient activation of insulin receptor tyrosine kinase by insulin [44], inhibition of PKB/akt, which regulates numerous metabolic systems within the cell, and degradation of insulin receptor [34, 35]. Apart from PKCE overexpression there was a shift in its cellular distribution towards the membrane, indicating its activation. PKCE and PKC $\alpha$ were correlated with muscle DAG content in Psammomys [35] and PKCO in high fat fed rats [45, 46]. However, in cultured myotubes obtained from IGT patients, the activation of PI3K and a non-DAG sensitive PKC $\zeta$ in response to insulin was decreased [47], which was interpreted as inducing insulin resistance. In human subjects an 


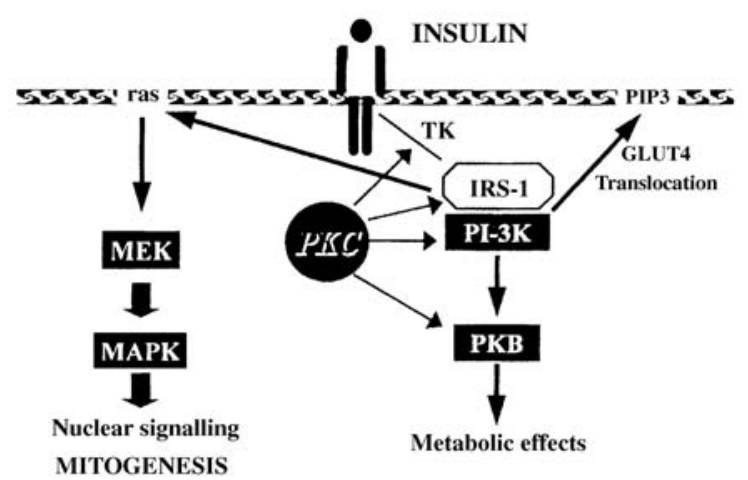

Fig. 3. Protein kinase $\mathrm{C}$ and insulin signaling pathway. The scheme illustrates the association of PKC overexpression (in particular PKCE in Psammomys obesus) and the attenuating action on insulin receptor tyrosine kinase (TK), phosphatidylinositol-3-kinase (PI3K) regulating the translocation of GLUT4 to the membrane and protein kinase B/akt. (Reproduced with permission from [35])

increase in circulating NEFA for a few hours, by lipid + heparin infusion, led to muscle DAG and PKC rise and insulin resistance [32]. The overall effect of PKC on muscle insulin signal transduction is shown in Fig. 3.

Muscle also contains a specific acetyl-CoA carboxylase, which produces malonyl-CoA. However, malonyl-CoA is not used further for fatty acid synthesis as muscles are deficient in fatty acid synthase effecting fatty acid elongation. Malonyl-CoA in muscle is a sensor of NEFA oxidation, its concentrations regulating the entry of LCFACoA into the mitochondria [48, 49]. In turn, the concentrations of malonyl-CoA, apart from acetyl-CoA carboxylase, are also regulated by malonyl-CoA decarboxylase and AMP-activated protein kinase [50]. In muscle, when acetyl-CoA carboxylase and malonyl-CoA are overexpressed, the entry of NEFA into the mitochondria and their oxidation becomes retarded and LCFACoA rise in concentration. As a result, DAG accumulation ensues, inducing PKC activation and insulin resistance by attenuation of the signalling pathway. Evidence of lower than normal muscle capacity to oxidise fatty acids in the clinical situation is also available. Obese women who reverted to normal weight after caloric restriction, did not respond to a fatty meal with appropriate fat oxidation compared with matched non-obese women [51]. A reduced capacity to oxidise fat was also shown in muscle samples of obese subjects [52]. Despite considerable uptake of palmitate, the muscle of diabetic patients released fewer oxidation products than healthy control subjects [53]. In contrast, muscle fat oxidation was enhanced when rat muscle acetyl-CoA carboxylase, malonyl-CoA decarboxylase and AMP protein kinase responded in opposite direction as a result of exercise [54].

\section{Other lipid substrates and cytokines involved in attenuation of insulin signaling}

It has been shown that the spingolipid ceramide, a major membrane component, can undergo lipolysis by sphigomyelinase, activated by $\mathrm{TNF} \alpha[55,56]$. This cytokine is secreted by adipose tissue and other tissues in diabesity and effects an inhibition of PKB/akt, IRS and of other components of the insulin signalling pathway in cultured muscle cells [57, 58]. Placental $\mathrm{TNF} \alpha$, mostly released into the maternal circulation, is considered to be partly responsible for the gestational insulin resistance in human pregnancy [59]. Adipose tissue also shows an endocrine-like activity and the abdominal fat is one of the most important risk factors for Type 2 diabetes. In addition to TNF $\alpha$, it is a prominent source of cytokines affecting tissue insulin sensitivity and beta-cell function [60]. They involve interleukin-6 [61], resistin [62] and adiponectin [63].

\section{Diabetes complications: atherosclerosis and hyperlipidaemia}

Among the diabetes complications, there is a pronounced acceleration of atherosclerosis, another process based on fat metabolism abnormality. Hyperglycaemia results in a plethora of advanced glycation products, giving rise to reactive oxygen molecules, which activate monocytes and macrophages, causing the proliferation of vascular smooth muscle cells and an overall diabetic angiopathy. One of the main actions in this process is the oxidation of the unsaturated fatty acids esterified to cholesterol in LDL [64]. The oxidized hydroperoxides of cholesterol esters impart a structural change in their apoB protein carrier and thus the LDL bind to surrogate scavenging receptors on macrophages due to nonrecognition by the genuine receptors [65]. The LDL accumulate in atherosclerotic plaques by association with intimal proteoglycans, facilitate macrophage - foam cell conversion, endothelial deposition and smooth muscle cell proliferation [66]. The presence of the scavenger receptor in smooth muscle cells is increased by PKC $\alpha$ [67]. The increase in VLDL and LDL emphasises the role of cholesterol oxidation in the accelerated atherogenesis in diabetes.

Dyslipidaemia plays an important role in diabetic complications, especially cardiovascular disease [68, 69]. The major lipoprotein abnormality in Type 2 diabetes is increased VLDL synthesis, in part due to the hepatic recirculation of NEFA outflowing in excess from adipose tissue, and in part as a result of de novo synthesis in the presence of hyperglycaemia and hyperinsulinaemia. This occurs because the hepatic VLDL synthesis, usually suppressed by insulin, continues unabated in the condition of insulin resistance 
[70]. There is also an impediment in VLDL and chylomicron removal due to lower than normal lipoprotein lipase (LPL) activity in adipose tissue in diabetes $[71,72,73]$. Changes in VLDL composition, such as excessive triglyceride and low apoE contents [74], can also reduce the LPL activity.

The volume of VLDL particles is of major importance in the atherogenicity in diabetes by determining the size and cholesterol content of the ensuing LDL particles. Large VLDL particles with high triglyceride content are the precursors of small, dense LDL, which determine the severity of atherosclerosis [76, 77]. The activity of cholesterol ester transfer protein (CETP), exchanging triglyceride for cholesterol in hypertriglyceridemic VLDL is increased in diabetes [78]. CETP could contribute to the formation of atherogenic lipoprotein phenotype of diabetes by producing VLDL particles rich in cholesterol and HDL rich in triglyceride not functioning well in the uptake of cholesterol from LDL and from the vessel wall [79].

VLDL in diabetes contain increased Apo B48 of intestinal origin $[80,81]$, indicating that the diabetic dyslipidaemia is a postprandial metabolic disorder. Improvement in diabetic control reduces the ApoB48 concentrations in VLDL [82]. The avid binding of ApoB48 to the intima, smooth muscle cells and macrophages indicates the presence of high receptor affinity and could explain the preferential appearance of ApoB48 derived from the large VLDL in the atherosclerotic plaques $[83,84]$.

\section{Diabetic complications: fatty acid and PKC-related complications}

Hyperglycaemia in poorly controlled Type 1 diabetes or beta-cell deficient Type 2 diabetes is the main reason for complications as established in the DCCT and UKPDS studies. Nephropathy, neuropathy and retinopathy, have also been indicated as associated with increased oxidative stress and flawed fat metabolism, including vascular contractility, basement membrane thickening, extracellular matrix expansion, microangiopathy and macroangiopathy. Many biochemical and pathological lesions in these insulin independent tissues have been associated with the DAG-sensitive $\mathrm{PKC}$ isoenzymes and have been related to changes in $\mathrm{Na}^{+} \mathrm{K}^{+}$ATPase activity, and MAP kinase. Among the $\mathrm{PKC}$ isoenzymes overexpressed in these tissues and actively investigated with a specific inhibitor are $\mathrm{PKC} \beta_{2}$ and PKC $\delta$ [85].

\section{NEFA, triglyceride and beta-cell lipotoxicity}

NEFA are known to be insulinotropic [86]. This property represents a very important protection against hy- poinsulinaemia on fasting, when the glucose is not available for the stimulation of the pancreatic insulin secretion. The increased mobilisation of NEFA from adipose tissue provides enough insulin to ensure a minimal insulin level necessary for preventing unrestrained NEFA outpour with ketosis.

However, a large inflow of NEFA and an accumulation of triglycerides in beta cells have a negative effect on insulin secretion. In massive obesity with excessive NEFA flow the increased secretion pressure results in beta-cell deterioration up to apoptosis. This has been shown in ZDF rats on relatively high fat diets [87], in Psammomys obesus on a high energy diet in the terminal stage characterized by hypoinsulinaemia and an increase in plasma NEFA and triglyceride concentrations [88] and in isolated islets exposed to high NEFA concentrations [89, 90]. The triglyceride content of beta cells increased, intracellular lipolysis raised the NEFA concentration, insulin stores became depleted and the response to glucose was minimal. In human islets preculturing with NEFA caused a caspase-mediated apoptosis possibly involving the ceramide pathway [91].

\section{Fat metabolism targeted antidiabetic modalities}

Most drugs used in Type 2 diabetes affect fat metabolism albeit in an indirect fashion. However, one of the prominent mechanisms for the increase of insulin sensitivity in muscle and liver by thiazolidinediones (TZD) is their effect on PPAR $\gamma$ receptors in adipose tissue. They promote preadipocyte proliferation, sensitise the inhibition of triglyceride lipolysis by insulin $[92,93,94]$, which results in triglyceride retention in adipose tissue and reduction of NEFA availability in the circulation. As discussed above, this prevents the ectopic fat deposition and the development of insulin resistance. Similarly, TZD reduce NEFA oxidation and glucose production in the liver [95]. Perhaps the most impressive model showing this aspect of TZD action is the fat-depleted transgenic mouse model [96, 97]. Because of the non-availability of fat substrate, muscle insulin responsiveness was very high but could be reversed by fat implantation. Similarly, the surgical excision of visceral fat in ageing Zucker diabetic and FBN insulin-resistant rats markedly improved the peripheral and hepatic insulin action [98]. In high fat fed rats, treatment with another TZD, BRL49653, reduced systemic NEFA and pronouncedly improved insulin action and glucoregulation [99]. Treatment with rosiglitazone of Type 2 diabetic patients resulted in a shift of skeletal muscle, mesenteric and hepatic and beta-cell triglyceride content to extracellular sites; hyperinsulinaemic-euglycaemic clamp demonstrated a remarkable improvement in glucose metabolism and an inhibitory activity on adipocyte lipolysis [100]. 


\section{Conclusion}

We invite comments as to what extent the accumulating evidence indicates that multiple aberrations in fat metabolism, reviewed above, play a pivotal role in the abnormalities of glucose homeostasis in diabetes. In our view the new findings of ectopic fat deposition in muscles and other tissues, linked to DAG accumulation and activation of DAG-sensitive PKC isoenzymes, are responsible for the emerging insulin resistance and beta-cell dysfunction, with the transition to full-fledged Type 2 diabetes. These findings implicate the derangements in fat metabolism as the main culprit of metabolic deviations in Type 2 diabetes: the negative feedback of the insulin signalling pathway. We maintain that these findings clarify the pathophysiology of diabetes and require redefinition of the glucocentric versus lipocentric approach. Our recommendation is as a first step to drop the adjective "mellitus" from diabetes and then to consider the introduction of a new adjective "lipidus" or "lipomellitus".

\section{References}

1. Dole VP (1956) A relation between nonesterified fatty acids in plasma and the metabolism of glucose. J Clin Invest 35:150-154

2. Gordon RS Jr, Cherkes A (1956) Unesterified fatty acid in human blood plasma. J Clin Invest 35:206-212

3. Reshef L, Shafrir E, Shapiro B (1958) In vitro release of unesterified fatty acids by adipose tissue. Metabolism 7:723-730

4. Ruderman NB, Toews CJ, Shafrir E (1969) Role of free fatty acids in glucose homeostasis. Arch Intern Med 123:299-313

5. Shafrir E, Gutman A (1965) Patterns of decrease of free fatty acids during glucose tolerance tests. Diabetes 14:7783

6. Zierler KL, Rabinowitz D (1964) Effect of very small concentrations of insulin on forearm metabolism. Persistence of its action on potassium and free fatty acids without its effect on glucose. J Clin Invest 43:950-962

7. Randle PJ, Garland PB, Hales CN, Newsholme EA (1963) The glucose fatty-acid cycle: Its role in insulin sensitivity and the metabolic disturbances of diabetes mellitus. Lancet 1:785-789

8. Randle PJ, Kerbey AL, Espinal J (1988) Mechanisms decreasing glucose oxidation in diabetes and starvation: role of lipid fuels and hormones. Diabetes Metab Rev 4:623638

9. Oliver MF (2002) Metabolic causes and prevention of ventricular fibrillation during acute coronary syndromes. Am J Med 112:305-311

10. Jouven X, Charles M-A, Desnos M, Ducimetiere P (2001) Circulating nonesterified fatty acid level as a predictive risk factor for sudden death in the population. Circulation 104:756-767

11. McGarry JD (1992) What if Minkowski had been ageusic? An altenative angle on diabetes. Lancet 258:766-770

12. Mering J von, Minkowski O (1890) Diabetes mellitus nach Pankreas-extirpation. Arch Exp Path Pharmakol. 26:371387
13. Golay A, Felber JP, Jequier E, DeFronzo RA, Ferrannini E (1988) Metabolic basis of obesity and noninsulin-dependent diabetes mellitus. Diabetes Metab Rev 4:727-747

14. Shulman GI (2000) Cellular mechanisms of insulin resistance. J Clin Invest 106:171-176

15. Boden G (1997) Role of fatty acids in the pathogenesis of insulin resistance and NIDDM. Diabetes 46:3-10

16. Waldhäusl WK, Roden M (2000) The effects of free fatty acids on glucose transport and phosphorylation in human skeletal muscle. Curr Opin Endocrinol Diabetes 7:211216

17. Roden M, Price TB, Perseghin G et al. (1996) Mechanism of free fatty acid-induced insulin resistance in humans. J Clin Invest 97:2859-2856

18. Krebs M, Krssak M, Nowotny P et al. (2001) Free fatty acids inhibit the glucose-stimulated increase of intramuscular glucose-6-phosphate concentration in humans. J Clin Endocrinol Metab 86:2153-2160

19. Sinha R, Dufour S, Petersen KF, LeBon V et al. (2002) Assessment of skeletal muscle triglyceride content by ${ }^{1} \mathrm{H}$ nuclear magnetic resonance spectroscopy in lean and obese adolescents. Diabetes 5:1022-1027

20. Pan DA, Lillioja S, Kriketos AD et al. (1997) Skeletal muscle triglyceride concentrations are inversely related to insulin action. Diabetes 46:983-988

21. Ebeling P, Essen-Gustavsson B, Tuominen JA, Koivisto VA (1998) Intramuscular triglyceride content is increased in IDDM. Diabetologia 41:111-115

22. Krssak M, Petersen KF, Dresner A, DiPietro L, et al. (1999) Intramyocellular lipid concentrations are correlated with insulin sensitivity in European and South Asian men. Diabetologia 42:932-935

23. Szczepaniak LS, Babcock EE, Schick F et al. (1999) Measurement of intracellular triglyceride stores by ${ }^{1} \mathrm{H}$ spectroscopy: validation in vivo. Am J Physiol 276: E977E989

24. Dresner A, Laurent D, Marcucci M et al. (1999) Effects of free fatty acids on glucose transport and IRS-1-associated phosphatidylinositol 3-kinase activity. J Clin Invest 103:253259

25. Man ZW, Hirashima T, Mori S, Kawano K (2000) Decrease in triglyceride accumulation in tissues by restricted diet and improvement of diabetes in Otsuka Long-Evans Tokushima fatty rats, a non-insulin-dependent diabetes model. Metabolism 49:108-114

26. Greco AV, Mingrone G, Giancaterini A et al. (2002) Insulin resistance in morbid obesity. Reversal with intramyocellular fat depletion. Diabetes 51:144-151

27. Houmard JA, Tanner CJ, Chunli Y et al. (2002) Effect of weight loss on insulin sensitivity and intramuscular longchain fatty acyl-CoAs in morbidly obese subjects. Diabetes 51:2959-2963

28. McGarry JD (2002) Dysregulation of fatty acid metabolism in the etiology of type 2 diabetes (Banting Lecture 2001). Diabetes 51:7-18

29. Ellis BA, Poynten A, Lowy AJ et al. (2000) Long-chain acyl-CoA esters as indicators of lipid metabolism and insulin sensitivity in rat and human muscle. Am J Physiol Endocrinol Metab 279: E554-E560

30. Itani SI, Ruderman NB, Schmieder F, Boden G (2002) Lipid-induced insulin resistance in human muscle is associated with changes in diacylglycerol, protein kinase $\mathrm{C}$, and I $\kappa$ B- $\alpha$. Diabetes 51:2005-2011

31. Dobbins RL, Szczepaniak LS, Bentley B et al. (2001) Prolonged inhibition of muscle carnitine palmitoyltransferase1 promotes intramyocellular lipid accumulation and insulin resistance in rats. Diabetes 50:123-130 
32. Griffin ME, Marcucci MJ, Cline GW et al. (1999) Free fatty acid-induced insulin resistance is associated with activation of protein kinase $\mathrm{C} \theta$ and alterations in the insulin signaling cascade. Diabetes 48:1270-1274

33. Shafrir E, Ziv E, Mosthaf L (1999) Nutritionally induced insulin resistance and receptor defect leading to $\beta$-cell failure in animal models. Annals NY Acad Sci 892:223-246

34. Shafrir E (2001) Albert Renold Memorial Lecture: molecular background of nutritionally induced insulin resistance leading to type 2 diabetes-from animal models to humans. Int J Exp Diabetes Res 2:299-319

35. Ikeda Y, Olsen GS, Ziv E et al. (2001) Cellular mechanism of nutritionally induced insulin resistance in Psammomys obesus. Overexpression of protein kinase $\mathrm{C} \varepsilon$ in skeletal muscle precedes the onset of hyperinsulinemia and hyperglycemia. Diabetes 50:584-592

36. Yu HY, Inoguchi T, Kakimoto M et al. (2001) Saturated non-esterified fatty acids stimulate de novo diacylglycerol synthesis and protein kinase $\mathrm{C}$ activity in cultured aortic smooth muscle cells. Diabetologia 44:614-620

37. Idris I, Gray S, Donnelly R (2001) Protein kinase C activation: isozyme-specific effects on metabolism and cardiovascular complications in diabetes. Diabetologia 44:659673

38. Seedorf K, Shearman M, Ullrich A (1995) Rapid and longterm effects of protein kinase $\mathrm{C}$ on receptor tyrosine kinase phosphorylation and degradation. J Biol Chem 270:1895318960

39. deVente JE, Carey JO, Bryant WO, Pettit GJ, Ways DK (1996) Transcriptional regulation of insulin receptor substrate 1 by protein kinase C. J Biol Chem 271:32276-32280

40. Danielsen AG, Liu F, Hosomi Y, Shii K, Roth RA (1995) Activation of protein kinase $\mathrm{C} \alpha$ inhibits signaling by members of the insulin receptor family. J Biol Chem 270:21600-21605

41. Tanti JF, Gremeaux T, Van Obberghen E, Le MarchandBrustel Y (1994) Serine/threonine phosphorylation of insulin receptor substrate 1 modulates receptor signaling. J Biol Chem 269:6051-6057

42. Chin JE, Liu F, Roth RA (1994) Activation of protein kinase $\mathrm{C} \alpha$ inhibits insulin-stimulated tyrosine phosphorylation of insulin receptor substrate-1. Mol Endocrinol 8:51-58

43. Muller HK, Kellerer M, Ermel B et al. (1991) Prevention by protein kinase $\mathrm{C}$ inhibitors of glucose-induced insulinreceptor tyrosine kinase resistance in rat fat cells. Diabetes 40:1440-1448

44. Kanety H, Moshe S, Shafrir E et al. (1994) Hyperinsulinemia induces a reversible impairment in insulin receptor function leading to diabetes in the sand rat model of noninsulin-dependent diabetes mellitus. Proc Natl Acad Sci USA 91:1853-1857

45. Schmitz-Peiffer C, Browne CL, Oakes ND et al. (1997) Alterations in the expression and cellular localization of protein kinase $C$ isozymes $\varepsilon$ and $\theta$ are associated with insulin resistance in skeletal muscle of the high-fat-fed rat. Diabetes 46:169-178

46. Kraegen EW, Carey DGP, Campbell LV (2000) Effects of lipids on blood glucose regulation and insulin action. In: Draznin B, Rizza R (eds) Clinical research in diabetes and obesity, Part I: Methods, assessment and metabolic regulation. Humana Press, Totova, NJ, pp 305-320

47. Vollenweider P, Menard B, Nicod P (2002) Insulin resistance, defective insulin receptor substrate 2-associated phosphatidylinositol-2' kinase activation, and impaired atypical protein kinase $\mathrm{C}(\zeta / \lambda)$ activation in myotubes from obese patients with impaired glucose tolerance. Diabetes 51:1052-1059
48. Ruderman NB, Saha AK, Vavvas D, Eitters LA (1999) Malonyl-CoA, fuel sensing, and insulin resistance. Am J Physiol 276: E1-E18

49. Shafrir E, Ziv E, Saha AK, Ruderman NB (2002) Regulation of muscle malonyl-CoA levels in the nutritionally insulin-resistant desert gerbil, Psammomys obesus. Diabetes Metab Res Rev 18:217-223

50. Saha AK, Schwarsin AJ, Roduit R et al. (2000) Activation of malonyl-CoA decarboxylase in rat skeletal muscle by contraction and the AMP-activated protein kinase activator 5-aminoimidazole-4-carboxamide-1-beta-D-ribofuranoside. J Biol Chem 275:24279-24283

51. Astrup A, Buemann B, Christensen NJ, Toubro S (1994) Failure to increase lipid oxidation in response to increasing dietary fat content in formerly obese women. Am J Physiol 266: E592-E599

52. Kelley DE, Goodpaster B, Wing RR, Simoneau JA (1999) Skeletal muscle fatty acid metabolism in association with insulin resistance, obesity and weight loss. Am J Physiol 277: E1130-E1141

53. Blaak EE, Wagenmaker AJM (2002) The fate of [U-13C] palmitate extracted by skeletal muscle in subjects with type 2 diabetes and control subjects. Diabetes 51:784-789

54. Park H, Kaushik VK, Constant S et al. (2002) Coordinate regulation of malonyl-CoA decarboxylase, sn-glycerol-3phosphate acyltransferase and acetyl-CoA carboxylase by AMP-activated protein kinase in rat tissues in response to exercise. J Biol Chem 277:32571-32577

55. Hotamisligil GS, Murray D, Choy LN, Spiegelman BM (1994) Tumor necrosis fact $\alpha$ inhibits signaling from the insulin receptor. Proc Natl Acad Sci USA 91:4854-4858

56. Hotamisligil GS, Peraldi P, Budavari A et al. (1996) IRS-1mediated inhibition of insulin receptor tyrosine kinase activity in TNF-alpha- and obesity-induced insulin resistance. Science 271:665-668

57. Paz H, Hemi R, LeRoith D et al. (1998) Elevated serine/threonine phosphorylation of IRS-1 and IRS-2 inhibits their binding to the juxtamembrane region of the insulin receptor and impairs their ability to undergo insulin-induced tyrosine phosphorylation. J Biol Chem 272:29911-29918

58. Schmitz-Peiffer C, Craig DL, Biden TJ (1999) Ceramide generation is sufficient to account for the inhibition of the insulin-stimulated PKB pathway in C2C12 skeletal muscle cells pretreated with palmitate. J Biol Chem 274:24202-24210

59. Kirwan JP, Hauguel-De Mouzon S, Lepercq J, Challier J-C (2002) TNF- $\alpha$ is a predictor of insulin resistance in human pregnancy. Diabetes 51:2207-2213

60. Greenberg AS, McDaniel ML (2002) Identifying the links between obesity, insulin resistance and $\beta$-cell function: potential role of adipocyte-derived cytokines in the pathogenesis of type 2 diabetes. Eur J Clin Invest 32:24-34

61. Mohamed-Ali V, Goorick S, Rawesh A et al. (1997) Subcutaneous adipose tissue releases interleukin-6, but not tumor necrosis factor- $\alpha$ in vivo. J Clin Endocrinol Metabl $82: 4196-4200$

62. Steppan CM, Bailey ST, Bhat S et al. (2001) The hormone resistin links obesity to diabetes. Nature 409:307-312

63. Weyer C, Funahashi T, Tanaka S et al. (2001) Hypoadiponectinemia in obesity and type 2 diabetes: close association with insulin resistance and hyperinsulinemia. J Clin Endocrinol Metab 86:1930-1935

64. Steinberg D, Parthasarathy S, Carew TE et al. (1989) Beyond cholesterol: modifications of LDL which increase its atherogenicity. N Engl J Med 320:915-923

65. Brown MS, Goldstein JL (1983) Lipoprotein metabolism in the macrophage: implications for cholesterol deposition in atherosclerosis. Annu Rev Biochem 52:223-261 
66. Porter NA, Caldwell SE, Mills KA (1995) Mechanisms of free radical oxidation of unsaturated lipids. Lipids 30:277-290

67. Mietus-Snyder M, Friera A, Glass CK, Pitas RE (1977) Regulation of scavenger receptor expression in smooth muscle cells by protein kinase C. A role for oxidative stress. Arterioscler Thromb Vasc Biol 17:v969-978

68. Owens D, Tomkin GH (2003) Diabetes dyslipidaemia: novel treatment and prognosis in type 1 and type 2 diabetes. In: Raz I, Skyler J, Shafrir E (eds) Diabetes: from research to diagnosis and treatment. Martin Dunitz, London, pp 93-120

69. Laakso M, Lehto S, Penttila I, Pyorala K (1993) Lipids and lipoproteins predicting coronary heart disease mortality and morbidity in patients with non-insulin-dependent diabetes. Circulation 88:1421-1430

70. Malmstrom R, Packard CJ, Caslake MJ et al. (1997) Defective regulation of triglyceride metabolism by insulin in the liver in NIDDM. Diabetologia 40:454-462

71. Goldberg IJ (1996) Lipoprotein lipase and lipolysis: central roles in lipoprotein metabolism and atherogenesis. J Lipid Res 37:693-707

72. De Man FH, Cabezas MC, Van Barlingen HH et al. (1996) Triglyceride-rich lipoproteins in non-insulin-dependent diabetes mellitus: post-prandial metabolism and relation to premature atherosclerosis. Eur J Clin Invest 26:89-108

73. Taskinen MR (1987) Lipoprotein lipase in diabetes. Diabetes Metab Rev 3:551-570

74. Bar-On H, Levy E, Oschry Y, Ziv E, Shafrir E (1984) Removal defect of very-low-density lipoproteins from diabetic rats. Biochim Biophys Acta 793:115-118

75. Gaw A, Packard CJ, Lindsay GM et al. (1995) Overproduction of small, very low density lipoproteins (sf 20-60) on moderate hypercholesterolaemia: relationship between apolipoprotein B kinetics and plasma lipoproteins. J Lipid Res 36:158-171

76. Taskinen MR (2001) Pathogenesis of dyslipidemia in Type 2 diabetes. Exp Clin Endocrinol Diabetes 109 [Suppl 2]:173-181

77. Tkac I, Kimball BP, Lewis G et al. (1997) The severity of coronary atherosclerosis in Type 2 diabetes mellitus is related to the number of circulating triglyceride-rich lipoprotein particles. Arterioscler Thromb Vasc Biol 17:3633-3638

78. Riemens S, Tol A van, Sluiter W et al. (1998) Elevated plasma cholesteryl ester transfer in NIDDM: Relationships with apolipoprotein B-containing lipoproteins and phospholipid transfer protein. Atherosclerosis 140:71-79

79. Lahdenpera S, Syvanne M, Kahri J, Taskinen M-R (1996) Regulation of low density lipoprotein particle size and distribution in NIDDM and coronary artery disease: importance of serum triglycerides. Diabetologia 39:453-461

80. Taggart C, Gibney K, Owens D et al. (1997) The role of dietary cholesterol in the regulation of postprandial apolipoprotein B48 levels in diabetes. Diabetes Med 14:10511058

81. Battula SB, Fitzsimons O, Moreno S et al. (2000) Postprandial apolipoprotein B48 and B100-containing lipoproteins in Type 2 diabetes: Do statins have a specific effect on triglyceride metabolism? Metabolism 49:1-7

82. Packard CJ, Demant T, Stewart JP et al. (2000) Apolipoprotein $\mathrm{B}$ metabolism and the distribution of VLDL and LDL subfractions. J Lipid Res 41:305-318

83. Gianturco SH, Ramprasad MP, Song R et al. (1998) Apolipoprotein B48 or its apolipoprotein B100 equivalent mediates the binding of triglyceride-rich lipoproteins to their unique human monocyte-macrophage receptor. Arterioscler Thromb Vasc Biol 18:968-976
84. Brown ML, Ramprasad PM, Umeda PK et al. (2000) A macrophage receptor for apo B48: cloning, expression and atherosclerosis. Proc Natl Acad Sci USA 97:74887493

85. Jacobs JRC, Evcimen ND, King GL (2003) New treatments for prevention of insulin resistance and diabetes complications: PKC involvement. In: Raz I, Skyler JS, Shafrir E (eds) Diabetes: from research to diagnosis and treatment. Martin Dunitz, London, pp 455-478

86. Crespin SR, Greenough WB, Steinberg D (1973) Stimulation of insulin secretion by long-chain free fatty acids. A direct pancreatic effect. J Clin Invest 52:1979-1984

87. Pick A, Clark J, Kubstrup C, et al. (1998) Role of apoptosis in failure of $\beta$-cell mass compensation for insulin resistance and $\beta$-cell defects in the male Zucker diabetic fatty rat. Diabetes 47:358-364

88. Shafrir E, Ben-Sasson R, Ziv E, Bar-On H (1999) Insulin resistance, $\beta$-cell survival, and apoptosis in type 2 diabetes: animal models and human implications. Diabetes Rev 7:114-123

89. Lee Y, Hirose H, Ohneda M, Johnson JH, McGarry JD, Unger RH (1994) $\beta$-cell lipotoxicity in the pathogenesis of non-insulin-dependent diabetes mellitus of obese rats fed a high fat diet. Proc Natl Acad Sci USA 91:1087810882

90. Unger RH (1995) Lipotoxicity in the pathogenesis of obesity-dependent NIDDM: Genetic and clinical implications. Diabetes 44:863-870

91. Lupi R, Dotta F, Marselli L, et al. (2002) Prolonged exposure to free fatty acids has cytostatic and pro-apoptotic effects on human pancreatic islets. Diabetes 51:14371442

92. Racette SB, Davis AO, McGill JB, Klein S (2002) Thiazolidinediones enhance insulin-mediated suppression of fatty acid flux in type 2 diabetes mellitus. Metabolism 51:169-174

93. Ciaraldi TP, Kong APS, Chu NV, Kim DD (2002) Regulation of glucose transport and insulin signaling by troglitazone or metformin in adipose tissue of type 2 diabetic subjects. Diabetes 51:30-36

94. McTernan PG, Harte AL, Anderson LA, et al. (2002) Insulin and rosiglitazone regulation of lipolysis and lipogenesis in human adipose tissue in vitro. Diabetes 51:1493-1498

95. Fulgencio J-P, Kohl C, Girard J, Pegorier J-P (1996) Troglitazone inhibits fatty acid oxidation and esterification, and gluconeogenesis in isolated hepatocytes from starved rats. Diabetes 45:1556-1562

96. Kim JK, Gavrilova O, Chen Y, Reitman ML, Shulman GI (2000) mechanism of insulin resistance in A-ZIP/F-1 fatless mice. J Biol Chem 275:8456-8460

97. Gavrilova O, Marcus-Samuels B, Graham D et al. (2000) Surgical implantation of adipose tissue reverses diabetes in lipoatrophic mice. J Clin Invest 105:271-278

98. Gabriely I, Ma XH, Yang X et al. (2002) Removal of visceral fat prevents insulin resistance and glucose intolerance of aging: an adipokine-mediated process? Diabetes 51:2951-2958

99. Oakes ND, Camilleri S, Furler SM et al. (1997) The insulin sensitizer, BRL 49653, reduces systemic fatty acid supply and utilization and tissue lipid availabiliaty in the rat. Metabolism 46:935-942

100. Mayerson AB, Hundal RS, Dufour S et al. (2002) The effects of rosiglitazone on insulin sensitivity, lipolysis, and hepatic and skeletal muscle triglyceride content in patients with type 2 diabetes. Diabetes 51:797802 